\title{
Agreement between patient-reported and provider-reported choice of contraceptive method among family planning patients in New York City: implications for public health
}

\author{
This article was published in the following Dove Press journal: \\ International Journal of Women's Health \\ 29 August 2013 \\ Number of times this article has been viewed
}

\section{Alicia Ventura \\ Samantha Garbers \\ Allison Meserve \\ Mary Ann Chiasson}

Research and Evaluation Unit, Public Health Solutions, New York, NY, USA
Correspondence: Samantha Garbers Public Health Solutions, 40 Worth Street, 5th Floor, New York, NY 10013 , USA

Tel + I 6466196675

Fax +I 6466196777

Emailsgarbers@healthsolutions.org

\begin{abstract}
National data on choice of contraceptive method and subsequent use are critical for monitoring progress toward meeting public health goals in reducing unintended pregnancy in the US. Yet few studies have focused on the reliability of clinically-reported or patient-reported measures of choice of contraceptive method for the range of available contraceptive methods. Among 1,844 women receiving reproductive health care at two federally funded centers in New York City, choice of contraceptive method at the end of the visit from two data sources was compared, ie, patient self-report, and provider-report as recorded in the clinical-administrative database. Agreement between the two data sources was assessed for the sample. Sociodemographic predictors of agreement were assessed using logistic regression. Agreement between the data sources was also assessed on a method-by-method basis using positive specific agreement. Participants were predominantly Latina (69\%), foreign-born (76\%), and low-income (99\% with incomes $<200 \%$ federal poverty level). Agreement of patient-reported and provider-reported contraceptive choice was highest for hormonal methods (positive specific agreement 94.0\%) and intrauterine devices $(89.9 \%)$, and lowest for condoms $(53.5 \%)$. In the logistic regression model, agreement was lower among teens aged 16-19 years compared with women aged 25+ years (odds ratio $0.74 ; 95 \%$ confidence interval $0.55-0.99$ ). Because teens are more likely to rely on condoms, the logistic regression model was repeated, adjusting for provider report of condom choice; after adjustment, no sociodemographic differences in agreement were observed. National data sources or studies relying on provider-reported method choice to derive estimates of contraceptive prevalence may overestimate choice of condoms. Our findings raise the question of whether condom choice can be accurately assessed by a single open-ended measure of choice of contraceptive method.
\end{abstract}

Keywords: contraception, condoms, methodology, service providers

\section{Introduction}

Unintended pregnancy is a serious public health concern in the US, because it has been found to result in adverse health outcomes for infants and women, ${ }^{1,2}$ including preterm delivery ${ }^{3,4}$ and increased rates of abortion. ${ }^{5}$ In the US, it is estimated that each year unintended pregnancies result in $\$ 4.6$ billion in direct medical costs, half of which is attributable to imperfect contraceptive use ${ }^{6}$ Consistent with other health indicators, the burden of unplanned pregnancy in the US is not evenly distributed across the population, with young, ${ }^{7-9}$ low-income, ${ }^{10,11}$ and minority women ${ }^{10,12}$ being disproportionately affected. These disparities in unintended pregnancy reflect disparities in contraceptive 
use, with young women, women of low socioeconomic status, and black women (compared with women of other races) being found to be less likely to use contraception or more likely to rely on less effective methods, such as condoms. . $^{5,10,13-16}$

Consistent use of effective contraceptive methods prevents unintended pregnancy; this ongoing behavior requires an individual to first make a choice among the available contraceptive methods. ${ }^{17-20}$ National data on choice of contraceptive method and its subsequent use, such as those reported in the National Survey of Family Growth, are critical to understanding the scope of unintended pregnancy as a public health issue, to estimating numbers of women at risk of unintended pregnancy, and to monitoring progress toward meeting public health goals in reducing unintended pregnancy. ${ }^{16,21-25}$ National data on choice of contraceptive method, as reported in clinical-administrative records, are also used to monitor and guide decisions about the allocation of funding for publicly supported family planning programs, such as the federal Title X program, which served 5.2 million women in the US in $2010 .^{26}$

In spite of the clinical and public health implications, few studies have focused on the reliability or validity of either clinically-reported or patient-reported measures of choice of contraceptive method for the range of available methods. A recent review of the literature concluded that information on the validity or reliability of self-reported measures of oral contraceptive choice or use was scarce. ${ }^{27}$ To address this gap, this study assessed agreement between patient-reported and provider-reported choice of contraceptive method at family planning clinic visits. Due to lack of a "gold standard" necessary to assess the validity of either patient-reported or provider-reported choice of contraceptive method, the aim of this study was to assess agreement, as a form of reliability, between the two sources of report.

\section{Materials and methods}

\section{Study design and setting}

The data used for this study were collected as part of ongoing quality assurance activities within a randomized controlled trial of a contraceptive assessment module at two clinics in New York City receiving Title $\mathrm{X}$ federal family planning funding (as reported elsewhere). ${ }^{28}$ All patient recruitment activities were carried out by two trained bilingual (Spanish/ English) project assistants between April 2008 and August 2010. Participants were recruited at time of visit and screened for eligibility. English-speaking or Spanish-speaking women age 16 years and over who had a family planning visit on the date of recruitment and were capable of providing informed consent were eligible for participation. Exclusion criteria included women at the clinic for a walk-in pregnancy test and women who were pregnant, seeking pregnancy, surgically sterilized, with a partner who was surgically sterilized, or those who had started menopause. The protocol was approved by the Public Health Solutions institutional review board. All study participants received family planning services according to existing standards of care.

In total, 2,448 women consented to participate in the randomized controlled trial. Of those women, 465 did not complete the end-of-visit survey that included patient report of choice of contraceptive method, and 139 were missing provider-reported contraceptive choice data in the clinical-administrative database, leaving a final sample of 1,844 women for these analyses.

\section{Collection of patient-reported data}

Eligible and consenting participants were given a touch screen laptop loaded with audio-computer-assisted selfinterviewing (ACASI) software. All participants were asked ten basic demographic questions using the ACASI computer prior to their clinic visit. All study participants completed a seven-question interviewer-administered survey immediately following the clinical visit. The survey asked "Which birth control method(s) did you get today?" All materials, including the ACASI survey and the end-of-visit survey, were available in both English and Spanish. In total, 11 patients reported choice of more than one method, with ten of these women reporting choice of condoms with another method; for these participants, the contraceptive method chosen was categorized as the most effective method reported, consistent with National Survey of Family Growth methodology. ${ }^{16}$

\section{Collection of provider-reported data}

Sociodemographic data, insurance status, and providerreported choice of contraceptive method at the end of the visit were exported from the existing clinical-administrative database of the participating family planning provider network. Per clinic protocols, choice of contraceptive method was documented by the clinical provider at the time of visit on a machine-readable form and then imported into the clinical-administrative database. The form included a list of all available contraceptive methods. Following completion of contraceptive counseling, the method(s) documented by the provider was that which the patient chose to either continue on or switch to, regardless of whether the provider was able to physically provide the patient with their chosen method at the time of visit or if a plan was put in place for 
the patient to obtain the method at a later time (eg, scheduled visit for insertion of an intrauterine device). The providerreported choice of contraceptive method as documented in the clinical-administrative database was used for these analyses; subsequent data cleaning was done for the efficacy analyses in the main trial. ${ }^{29}$ Consistent with the patient-reported data, in instances in which the provider reported choice of more than one method ( $\mathrm{n}=17 ; 16$ of these instances involved choice of condoms with another method), the choice of method was categorized as the most effective method recorded. ${ }^{16}$

\section{Outcome I: positive specific agreement}

Positive specific agreement was calculated to assess the level of agreement between the two information sources (ie, patient and provider) for each individual contraceptive method, as presented in Figure 1. Positive specific agreement measures the conditional probability that a source (eg, patient) will identify a positive outcome (eg, choice of a particular method) given that another randomly selected source (eg, provider) has also identified the same case as positive (ie, indicated choice of the same method). ${ }^{29}$ In other words, it is a measure of chance-corrected agreement that estimates the proportion of positive cases that were agreed upon (denoted as $a$ in Figure 1). Of relevance to this study, positive specific agreement can be used to approximate traditional measures of reliability, such as the $\mathrm{k}$ statistic, that require an accurate count of negative cases. In this study, the negative case count refers to instances where neither the provider nor the patient reported choice of the particular method for which agreement is being assessed (denoted as $d$ in Figure 1); these negative cases are not well defined or clinically relevant.

\section{Outcome 2: simple agreement}

For the entire sample and for selected sociodemographic subgroups, simple agreement was calculated as a proportion, ie, the number of instances where the provider and patient both reported the same choice of contraceptive method (or both reported no choice of method) divided by the total number of participants. This outcome measure was used for logistic regression models to compare overall agreement across subgroups.

\section{Statistical analyses}

Data analyses were done using Statistical Package for the Social Sciences version 20.0 software (SPSS Inc, Chicago, IL, USA). For each participant, choice of contraceptive method as reported by the patient and choice of contraceptive method as reported by the provider was cross-tabulated, and simple agreement was calculated. For each contraceptive method, positive specific agreement was calculated. Logistic regression analyses were conducted to examine each sociodemographic characteristic as a predictor of simple agreement. The logistic regression model was repeated, controlling for condom choice (as reported by the provider), to examine whether lower levels of simple agreement observed among some subgroups was explained by differing prevalence of condom choice.

\section{Results}

As shown in Table 1, the 1,844 participants were predominantly Latina (69\%), foreign-born (76\%), and lowincome. The mean age of participants was 28 years. Over half $(59 \%)$ of the sample did not have health insurance and $40 \%$ were covered by public insurance. According to income eligibility standards for public insurance and the provider network's sliding fee scale for uninsured patients, $99 \%$ of the sample had incomes below $200 \%$ of the federal poverty level. ${ }^{30}$

Positive specific agreement for each contraceptive method, as detailed in Table 2, varied widely. For some methods, positive specific agreement was high, ie, $82.8 \%$

\begin{tabular}{|c|c|c|c|}
\multicolumn{2}{c|}{} & \multicolumn{2}{c|}{$\begin{array}{c}\text { Provider-reported } \\
\text { contraceptive method }\end{array}$} \\
\cline { 3 - 4 } \multicolumn{2}{c|}{} & Yes & No \\
\hline $\begin{array}{l}\text { Patient-reported } \\
\text { contraceptive method }\end{array}$ & Yes & a & b \\
\cline { 2 - 4 } & No & c & d \\
\hline
\end{tabular}

Positive specific agreement given distribution of responses (Ppos): $\frac{2 a}{(2 a+b+c)}$

Figure I Calculation of positive specific agreement for each method. 
Table I Socio-demographic data of sample participants $(n=I, 844)$

\begin{tabular}{|c|c|c|}
\hline \multirow[t]{2}{*}{ Characteristic } & \multicolumn{2}{|c|}{ Total $(n=1,844)$} \\
\hline & $n$ & $\%$ \\
\hline \multicolumn{3}{|l|}{ Age at interview } \\
\hline $16-19$ & 265 & $14.4 \%$ \\
\hline $20-24$ & 402 & $21.8 \%$ \\
\hline $25-29$ & 458 & $24.8 \%$ \\
\hline $30-34$ & 366 & $19.8 \%$ \\
\hline 35 and older & 353 & $19.1 \%$ \\
\hline \multicolumn{3}{|l|}{ Race/ethnicity } \\
\hline Hispanic, any race & 1,260 & $69.3 \%$ \\
\hline Non-Hispanic black & 256 & $14.1 \%$ \\
\hline Non-Hispanic, other race & 301 & $16.6 \%$ \\
\hline \multicolumn{3}{|l|}{ Module language } \\
\hline English & 812 & $44.0 \%$ \\
\hline Spanish & 1,032 & $56.0 \%$ \\
\hline \multicolumn{3}{|l|}{ Educational attainment } \\
\hline Less than high school & 488 & $26.9 \%$ \\
\hline High school/GED & 732 & $40.3 \%$ \\
\hline Some college or higher & 595 & $32.8 \%$ \\
\hline \multicolumn{3}{|l|}{ Nativity } \\
\hline US-born & 438 & $23.9 \%$ \\
\hline Foreign-born & $\mathrm{I}, 397$ & $76.1 \%$ \\
\hline \multicolumn{3}{|l|}{ Insurance status } \\
\hline Public insurance & 740 & $40.1 \%$ \\
\hline Private insurance & 16 & $0.9 \%$ \\
\hline Uninsured & 1,088 & $59.0 \%$ \\
\hline
\end{tabular}

Abbreviation: GED, general equivalency diploma.

for the hormonal patch, $89.9 \%$ for intrauterine devices, and 93.4\% for oral contraceptives. Positive specific agreement was lowest for condoms (53.5\%) and no method (31.2\%). In the 358 instances in which the provider reported that condom use was the method choice, the patient reported that condom use was the method chosen in only 149 instances, while the patient reported that no method was chosen in 152 instances. The remaining 57 instances without agreement were evenly distributed across seven other methods.

For the entire sample of 1,844 participants, there was simple agreement in 1,406 instances (76.2\%). Simple agreement was lower among some subgroups: among teens aged 16-19 years simple agreement was $71.7 \%$ compared with $77.5 \%$ among women aged 25 years and over (odds ratio $0.74 ; 95 \%$ confidence interval $0.55-0.99$ ), and $71.9 \%$ among non-Hispanic black women compared with $78.4 \%$ among Hispanic women who completed participation in Spanish (odds ratio $0.71 ; 95 \%$ confidence interval $0.52-0.97$ ). Non-Hispanic black women were also more likely to have the provider report that they chose condoms (32.8\%) than Hispanic women who completed participation in Spanish $(15.8 \%)$. Because these subgroups (both in this sample and in national data reports) are more likely to rely on condoms, and because positive specific agreement for condoms was very low, the logistic regression model was repeated, adjusting for provider report of condom choice. In the adjusted model, these observed sociodemographic differences in simple agreement no longer remained (Table 3).

\section{Discussion}

In this study, agreement of patient-reported and providerreported contraceptive choice varied significantly by contraceptive method, and was highest for those methods most

Table 2 Positive specific agreement between provider report and patient report, by contraceptive method $(n=1,844)$

\begin{tabular}{|c|c|c|c|c|c|c|}
\hline Contraceptive method & $\begin{array}{l}\text { Method was reported } \\
\text { by both provider and } \\
\text { patient }(n=1,406)\end{array}$ & $\begin{array}{l}\text { Method was } \\
\text { reported by } \\
\text { provider } \\
(n=I, 844)\end{array}$ & $\begin{array}{l}\text { Method was } \\
\text { reported by } \\
\text { patient } \\
(n=I, 844)\end{array}$ & $\begin{array}{l}\% \text { of patients } \\
\text { agreeing with } \\
\text { provider-reported } \\
\text { method }\end{array}$ & $\begin{array}{l}\% \text { of providers } \\
\text { agreeing with } \\
\text { patient-reported } \\
\text { method }\end{array}$ & $\begin{array}{l}\text { Positive } \\
\text { specific } \\
\text { agreement }\end{array}$ \\
\hline IUDa & 360 & 406 & 395 & $88.7 \%$ & $91.1 \%$ & $89.9 \%$ \\
\hline Hormonal methods & 828 & 883 & 919 & $95.9 \%$ & $92.2 \%$ & $94.0 \%$ \\
\hline Depo-provera & 166 & 181 & 187 & $91.7 \%$ & $88.8 \%$ & $90.2 \%$ \\
\hline NuvaRing & 52 & 55 & 70 & $94.5 \%$ & $74.3 \%$ & $83.2 \%$ \\
\hline Patch & 12 & 16 & 13 & $75.0 \%$ & $92.3 \%$ & $82.8 \%$ \\
\hline Pill & 598 & 631 & 649 & $94.8 \%$ & $92.1 \%$ & $93.4 \%$ \\
\hline Condom & 149 & 358 & 199 & $41.6 \%$ & $74.9 \%$ & $53.5 \%$ \\
\hline No method & 69 & 142 & 322 & $48.6 \%$ & $21.4 \%$ & $31.2 \%$ \\
\hline Abstinence & 0 & 28 & I & - & - & - \\
\hline Sterilization or vasectomy ${ }^{b}$ & 0 & 3 & I & - & - & - \\
\hline Fertility awareness method & 0 & 3 & 2 & - & - & - \\
\hline Female barrier & 0 & 0 & 5 & - & - & - \\
\hline Spermicide & 0 & 3 & 0 & - & - & - \\
\hline Seeking pregnancy ${ }^{b}$ & 0 & 17 & 0 & - & - & - \\
\hline Pregnant ${ }^{b}$ & 0 & I & 0 & - & - & - \\
\hline
\end{tabular}

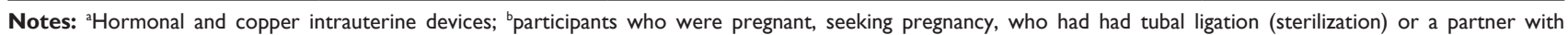
vasectomy were not eligible for the study. The 18 participants who were reported by the provider to be pregnant or seeking pregnancy reported, in the eligibility screening instrument, that they were neither pregnant nor seeking pregnancy. The 3 participants who were reported using sterilization by the provider and the I participant who reported choosing sterilization at the end of the visit also met all eligibility criteria at the start of the visit.

Abbreviation: IUD, intrauterine device. 
Table 3 Logistic regression models predicting simple agreement by sociodemographic subgroup, unadjusted and adjusted for provider report of condom choice $(n=1,844)$

\begin{tabular}{|c|c|c|c|c|c|c|}
\hline \multirow[t]{2}{*}{ Characteristic } & \multirow[t]{2}{*}{$\mathbf{n}$} & \multicolumn{2}{|c|}{$\begin{array}{l}\text { Simple } \\
\text { agreement }^{a}\end{array}$} & \multirow{2}{*}{$\begin{array}{l}\text { Unadjusted } \\
\text { OR (95\% Cl) }\end{array}$} & \multirow{2}{*}{$\begin{array}{l}\text { Provider reported } \\
\text { condom choice } \\
\% \\
\end{array}$} & \multirow{2}{*}{$\begin{array}{l}\text { Adjusted for provider } \\
\text { report of condom choice } \\
\text { OR }(95 \% \mathrm{Cl})\end{array}$} \\
\hline & & n & $\%$ & & & \\
\hline Entire sample & $\mathrm{I}, 844$ & 1,406 & $76.2 \%$ & - & $19.4 \%$ & - \\
\hline \multicolumn{7}{|l|}{ Age } \\
\hline $16-19$ & 265 & 190 & $71.7 \%$ & $0.74(0.55-0.99)$ & $26.8 \%$ & $0.90(0.65-1.26)$ \\
\hline $20-24$ & 402 & 304 & $75.6 \%$ & $0.90(0.69-1.18)$ & $21.4 \%$ & $1.00(0.75-1.34)$ \\
\hline 25 and older [ref] & $\mathrm{I}, \mathrm{I} 77$ & 912 & $77.5 \%$ & - & $17.1 \%$ & - \\
\hline \multicolumn{7}{|l|}{ Race/ethnicity } \\
\hline Non-Hispanic, black & 256 & 184 & $71.9 \%$ & $0.71(0.52-0.97)$ & $32.8 \%$ & $\mathrm{I} .05(0.74-1.49)$ \\
\hline Non-Hispanic, other & 301 & 222 & $73.8 \%$ & $0.78(0.57-1.05)$ & $19.9 \%$ & $0.83(0.60-1.16)$ \\
\hline Hispanic, English module & 336 & 251 & $74.7 \%$ & $0.82(0.61-1.09)$ & $19.0 \%$ & $0.86(0.63-1.18)$ \\
\hline Hispanic, Spanish module [ref] & 924 & 724 & $78.4 \%$ & - & $15.8 \%$ & - \\
\hline \multicolumn{7}{|l|}{ Educational attainment } \\
\hline Less than high school [ref] & 488 & 384 & $78.7 \%$ & - & $18.4 \%$ & - \\
\hline High school/GED & 732 & 553 & $75.5 \%$ & $0.84(0.64-1.10)$ & $19.5 \%$ & $0.84(0.62-1.13)$ \\
\hline Some college or higher & 595 & 444 & $74.6 \%$ & $0.80(0.60-1.06)$ & $20.5 \%$ & $0.81(0.59-1.10)$ \\
\hline \multicolumn{7}{|l|}{ Nativity } \\
\hline US-born & 438 & 322 & $73.5 \%$ & $1.21(0.94-1.54)$ & $27.2 \%$ & $0.94(0.72-1.24)$ \\
\hline Foreign-born [ref] & ।,397 & 1076 & $77.0 \%$ & - & $17.0 \%$ & - \\
\hline \multicolumn{7}{|l|}{ Insurance status } \\
\hline Public insurance & 740 & 563 & $76.1 \%$ & $0.98(0.79-1.22)$ & $19.9 \%$ & $1.00(0.78-1.26)$ \\
\hline Private insurance & 16 & 11 & $68.8 \%$ & $0.68(0.23-1.97)$ & $18.8 \%$ & $0.62(0.20-1.99)$ \\
\hline Uninsured [ref] & $\mathrm{I}, 088$ & 832 & $76.5 \%$ & - & $19.1 \%$ & - \\
\hline
\end{tabular}

Note: aSimple agreement: patient and provider both reported the same contraceptive method choice (or both reported no contraceptive method choice).

Abbreviation: GED, general equivalency diploma; ref, reference group.

effective at preventing pregnancy, such as hormonal methods (positive specific agreement, 94.0\%) and intrauterine devices $(89.9 \%)$. The high agreement in reporting of oral contraceptive choice is similar to that found in another study comparing patient-report and provider records of lifetime history of oral contraceptive use, which reported high agreement on the specific brand name for the most recent oral contraceptive used. ${ }^{31}$ Agreement was lowest for methods with lower typical use effectiveness, particularly condoms; in almost half of the instances in which the provider reported that the patient chose condoms, the patient reported choosing no method of contraception (152/358; positive specific agreement for condoms, 53.5\%). This low agreement between patient and provider is consistent with other research looking at selfreported condom use. ${ }^{32-36}$

Few recent studies in the US, with one exception, ${ }^{36}$ have examined the reliability of reported contraceptive method choice or use across the range of available methods, or have compared patient self-report with the clinical-administrative data sources that inform national data estimates. In our sample, the level of simple agreement (ie, the total amount of agreement between patients and providers for all methods combined) differed significantly among sociodemographic subgroups. However, these observed differences could all be explained by the low reliability of condom report rather than patient characteristics. Previous research using provider-reported data in similar clinical settings has found that non-Hispanic black adults and adolescents are more likely to choose condoms or other barrier methods than hormonal methods of contraception. ${ }^{14,37}$ Our findings suggest that providers may be over-reporting condom choice for these groups.

The findings of this study should be interpreted with consideration of some limitations. Slightly different question wording was used to collect provider-reported and patient-reported choice of contraceptive method after the clinic visit, and this variation in data collection methods could have contributed to low levels of simple agreement and positive specific agreement. Specifically, the wording of the survey used to measure patient-reported contraceptive method choice after the clinical visit ("Which method did you get today?") may have contributed to lower positive specific agreement for intrauterine devices in cases where the device was inserted prior to the clinic visit on the date of recruitment. It is plausible that in such instances the patient might have reported choice of no method of contraception and the provider might have reported intrauterine device as the method. Of the 404 instances in which the provider reported an intrauterine device, the patient also reported an intrauterine device in 360 instances (positive specific 
agreement, 89.9\%), and in only 36 instances the patient reported choosing no method.

Similarly, it is possible that the wording of the survey question used to measure patient-reported choice of contraceptive method contributed to the low positive specific agreement for condoms (53.5\%). However, at the time of this study, standard of care at the participating family planning clinics was to distribute condoms and provide relevant counseling to all patients at risk for acquiring a sexually transmitted infection regardless of the contraceptive method chosen. Although we do not have specific data on whether patients actually received condoms at each visit, given the wide availability of condoms in the clinics, it seems unlikely that confusion related to question wording would result in significant under-reporting of condom choice by patients.

Additionally, as noted in other studies, medical data captured in the use of administrative databases has low reliability, ${ }^{38}$ and provider-reported choice of method may have been subject to data entry errors in the clinicaladministrative database. Because assessing validity would have required us to consider the provider report (recorded in the clinical-administrative database) as a gold standard, our study examined agreement as a measure of reliability rather than validity. We did not have data on provider characteristics and were therefore unable to discern how individual provider behavior, which has been found to affect clinical outcomes in prior research, ${ }^{39}$ may have influenced the contraceptive method reported. Lastly, the study was conducted among a population of primarily foreign-born, low-income Latina women seeking clinical services at publicly funded family planning clinics in New York City, which limits the generalizability of these findings to other populations and settings. Women in our study sample were more likely to be Hispanic, foreign-born, Spanish-speaking, uninsured or publicly insured, younger, and with lower educational attainment than the general female population in New York City. ${ }^{40}$

Despite these limitations, the consistency of our choice of method data with US national data for publicly funded family planning centers suggests that these findings are likely to be of considerable relevance to providers and public health policymakers, both in the US and elsewhere, who rely on similar national data sources. ${ }^{41}$ Distribution of provider-reported choice of method after the clinic visit was compared with a national provider-reported primary contraceptive method mix, in the Family Planning Annual Report. ${ }^{42}$ The prevalence of condom choice in our sample as reported by the provider (19\%) was consistent with that reported in the 2009 Family Planning Annual Report for women who are not pregnant, seeking pregnancy, or relying on sterilization $(17 \%)$.

This similarity suggests that the providers in this study were not over-reporting condom choice as compared with a national sample of family planning providers. In our sample, in almost half of instances in which the provider reported condom choice, the patient reported receiving no method (152/358). Applying the positive specific agreement percentage for condoms found in this study to the number of women in the US reporting condom choice as reported in the 2009 Family Planning Annual Report, national family planning providers may be inaccurately reporting choice of male condoms for over 300,000 women in the US who have actually not chosen any method of contraception.

Accordingly, extrapolating national data on choice of contraceptive method to estimate use of contraception use merits additional caution. Contraceptive choice is not equivalent to contraceptive use, and should be conceptualized and measured as a distinct construct. Studies that have looked at both choice and use of methods have found that the proportion of participants actually using a particular method is significantly less than the proportion of patients who have chosen the same method. ${ }^{43,44}$ Data sources or studies that rely on provider-reported method choice to derive estimates of contraceptive prevalence may overestimate choice of condoms, and therefore may further overestimate use of condoms.

Additionally, the low reliability in the reporting of choice of method observed in our study suggests that attention should be given to the role that patient-provider interactions play in the reporting of choice of contraceptive method. Our findings raise the question of whether or not condom choice can be accurately assessed by a single open-ended measure of choice of contraceptive method, as is currently standard of practice. Future research, using more detailed assessments to establish a gold standard in reporting, is needed to determine the validity of provider-reported choice of contraceptive method, particularly for condoms.

\section{Acknowledgments}

This project was made possible by grants from the National Campaign to Prevent Teen and Unplanned Pregnancy, the Bridge the Gap Foundation, and a private foundation. The authors wish to thank the study participants; Diana Castillo, Sarina Jean-Louis, and the staff at MIC Women's Health Services; Melissa Kottke, and Robert Hatcher, and Peggy 
Goedken from Emory University; our reviewers, Roberta Scheinmann, and Sabina Hirshfield; and our interviewers, Rosanna Martinez, M Gabriela Pelaez-Ruiz, and Elizabeth Verdesoto.

\section{Disclosure}

The authors report no conflicts of interest in this work.

\section{References}

1. Gipson JD, Koenig MA, Hindin MJ. The effects of unintended pregnancy on infant, child, and parental health: a review of the literature. Stud Fam Plann. 2008;39(1):18-38.

2. Logan C, Holcombe E, Manolve J, Ryan S. The Consequences of Unintended Childbearing: A White Paper. Washington, DC: Child Trends Inc; 2007.

3. Orr ST, Miller CA, James SA, Babones S. Unintended pregnancy and preterm birth. Paediatr Perinat Epidemiol. 2000;14(4):309-313.

4. Mohllajee AP, Curtis KM, Morrow B, Marchbanks PA. Pregnancy intention and its relationship to birth and maternal outcomes. Obstet Gynecol. 2007;109(3):678-686.

5. Finer LB, Henshaw SK. Disparities in rates of unintended pregnancy in the United States, 1994 and 2001. Perspect Sex Reprod Health. 2006;38(2):90-96.

6. Trussell J, Henry N, Hassan F, Prezioso A, Law A, Filonenko A. Burden of unintended pregnancy in the United States: potential savings with increased use of long-acting reversible contraception. Contraception. 2013;87(2):154-161.

7. Kissin DM, Anderson JE, Kraft JM, Warner L, Jamieson DJ. Is there a trend of increased unwanted childbearing among young women in the United States? J Adolesc Health. 2008;43(4):364-371.

8. Pulley L, Klerman LV, Tang H, Baker BA. The extent of pregnancy mistiming and its association with maternal characteristics and behaviors and pregnancy outcomes. Perspect Sex Reprod Health. 2002;34(4):206-211.

9. Chandra A, Martinez GM, Mosher WD, Abma JC, Jones J. Fertility, family planning, and reproductive health of US women: data from the 2002 National Survey of Family Growth. Vital Health Stat. 2005;23(25):1-160.

10. Finer LB, Zolna MR. Unintended pregnancy in the United States: incidence and disparities, 2006. Contraception. 2011;84(5):478-485.

11. Trussell J, Wynn LL. Reducing unintended pregnancy in the United States. Contraception. 2008;77(1):1-5.

12. Cubbin C, Braveman PA, Marchi KS, Chavez GF, Santelli JS, Gilbert BJ. Socioeconomic and racial/ethnic disparities in unintended pregnancy among postpartum women in California. Matern Child Health J. 2002;6(4):237-246.

13. Foster DG, Bley J, Mikanda J, et al. Contraceptive use and risk of unintended pregnancy in California. Contraception. 2004;70(1):31-39.

14. Raine T, Harper C, Paukku M, Darney P. Race, adolescent contraceptive choice, and pregnancy at presentation to a family planning clinic Obstet Gynecol. 2002;99(2):241-247.

15. Dehlendorf C, Rodriguez MI, Levy K, Borrero S, Steinauer J. Disparities in family planning. Am J Obstet Gynecol. 2010;202(3):214-220.

16. Mosher WD, Jones J. Use of contraception in the United States: 1982-2008. Vital Health Stat 23. 2010;29:1-44.

17. Tsui AO, McDonald-Mosley R, Burke AE. Family planning and the burden of unintended pregnancies. Epidemiol Rev. 2010;32(1): 152-174.

18. Frost JJ, Finer LB, Tapales A. The impact of publicly funded family planning clinic services on unintended pregnancies and government cost savings. J Health Care Poor Underserved. 2008;19(3): 778-796.

19. Trussell J. The cost of unintended pregnancy in the United States. Contraception. 2007;75(3):168-170.
20. Trussell J, Guthrie K. Choosing a contraceptive: efficacy, safety and personal considerations. In: Hatcher R, Trussell J, Nelson AL, Cates W Jr, Kowal D, Policar M, editors. Contraceptive Technology. 20th ed. Atlanta, GA: Ardent Media; 2011.

21. Levi A, Dau KQ. Meeting the national health goal to reduce unintended pregnancy. J Obstet Gynecol Neonatal Nurs. 2011;40(6):775-781.

22. Taylor D, James EA. An evidence-based guideline for unintended pregnancy prevention. J Obstet Gynecol Neonatal Nurs. 2011;40(6): 782-793.

23. Matsuda Y, Masho S, McGrath JM. The relationship between repeated unintended pregnancies and current contraceptive use: National Survey of Family Growth (NSFG) 2006-2008 data. J Community Health Nurs. 2012;29(3):163-172.

24. Lepkowski JM, Mosher WD, Davis KE, Groves RM, Van Hoewyk J. The 2006-2010 National Survey of Family Growth: sample design and analysis of a continuous survey. Vital Health Stat 2. 2010;(150):1-36.

25. Gaydos L, Hogue CJ, Kramer MR. Riskier than we thought: revised estimates of noncontracepting women risking unintended pregnancy. Public Health Rep. 2006;121(2):155-159.

26. Fowler C, Lloyd S, Gable J, Wang J, Krieger K. Family Planning Annual Report: 2010 National Summary. Research Triangle Park, NC: RTI International; 2011.

27. Hall KS, White KO, Reame N, Westhoff C. Studying the use of oral contraception: a review of measurement approaches. $J$ Womens Health (Larchmt). 2010;19(12):2203-2210.

28. Garbers S, Meserve A, Kottke M, Hatcher RA, Ventura A, Chiasson MA. Randomized controlled trial of a computer-based contraceptive module to improve contraceptive method choice. Contraception. 2012;86(4):383-390.

29. Hripcsak G, Rothschild AS. Agreement, the F-measure, and reliability in information retrieval. J Am Med Inform Assoc. 2005;12(3): 296-298.

30. United States poverty guidelines updated periodically in the Federal Register by the US Department of Health and Human Services under the authority of 42 USC 9902(2). Washington, DC: US Department of Health and Human Services. Available from: http://www.census.gov/hhes/www/ poverty/data/threshld/index.html. Accessed August 19, 2013.

31. van Leeuwen FE, van Duijn CM, Camps MH, et al. Agreement between oral contraceptive users and prescribers: implications for case-control studies. Contraception. 1992;45(5):399-408.

32. Bearinger LH, Sieving RE, Duke NN, McMorris BJ, Stoddard S, Pettingell SL. Adolescent condom use consistency over time: global versus partner-specific measures. Nurs Res. 2011;60(Suppl 3): S68-S78.

33. Choi KH, Gregorich SE. Assessment of fully and partially condomprotected sex among US women: the potential for overestimating protected sex acts. Sex Transm Dis. 2011;38(5):445-447.

34. Lipovsek V, Longfield K, Buszin J. Can follow-up study questions about correct and consistent condom use reduce respondent over-reporting among groups at high risk? An analysis of datasets from six countries. Reprod Health. 2010;7:9.

35. Maggwa BN, Mati JK, Mbugua S, Hunter DJ. Validity of contraceptive histories in a rural community in Kenya. Int J Epidemiol. 1993;22(4): 692-697.

36. Sieving R, Hellerstedt W, McNeely C, Fee R, Snyder J, Resnick M. Reliability of self-reported contraceptive use and sexual behaviors among adolescent girls. $J$ Sex Health. 2005;42(2):159-166.

37. Dehlendorf C, Foster DG, de Bocanegra HT, Brindis C, Bradsberry M, Darney P. Race, ethnicity and differences in contraception among low income women: methods received by family PACT clients, California, 2001-2007. Perspect Sex Reprod Health. 2011;43(3): 181-187.

38. Grimes DA. Epidemiologic research using administrative databases. Obstet Gynecol. 2010;116(5):1018-1019.

39. van Ryan M, Fu SS. Paved with good intentions: do public health and human service providers contribute to racial/ethnic disparities in health? Am J Public Health. 2003;93(2):248-255. 
40. Burden AM. NYC 2010: Results from the 2010 Census, Population Growth and Race/Hispanic Composition. New York, NY: New York City Department of City Planning; 2011.

41. Bourne PA, Charles CA, Crawford TV, Kerr-Campbell MD, Francis C. Current use of contraceptive method among women in a middle-income developing country. Open Access Journal of Contraception. 2010;1:1.

42. Fowler CI, Gable J, Wang J, Lloyd SW. Family Planning Annual Report: 2009 National Summary. Research Triangle Park, NC: RTI International; 2010.
43. Minnis AM, Shiboski SC, Padian NS. Barrier contraceptive method acceptability and choice are not reliable indicators of use. Sex Transm Dis. 2003;30(7):556-561.

44. Oakley D, Sereika S, Bogue E. Oral contraceptive pill use after an initial visit to a family planning clinic. Fam Plann Perspect. 1991;23(4): $150-154$.

\section{Publish your work in this journal}

The International Journal of Women's Health is an international, peerreviewed open-access journal publishing original research, reports, editorials, reviews and commentaries on all aspects of women's healthcare including gynecology, obstetrics, and breast cancer. The manuscript management system is completely online and includes a very quick and fair peer-review system, which is all easy to use. Visit http://www.dovepress.com/testimonials.php to read real quotes from published authors.

Submit your manuscript here: http://www.dovepress.com/international-journal-of-womens-health-journal 